\title{
General and abdominal obesity prevelances and their relations with metabolic syndrome components
}

\author{
Olgun Goktas ${ }^{1}$, Canan Ersoy², \\ Ilker Ercan ${ }^{3}$, Fatma Ezgi Can ${ }^{4}$
}

\begin{abstract}
Objective: To evaluate the frequency of obesity and its relation of metabolic syndrome.

Methods: The data from the records of the consecutive adult residents of Bursa province in Turkey who were admitted to the family health centers from the $1^{\text {st }}$ January to the $31^{\text {st }}$ December 2016 were evaluated retrospectively. The population size was $2901396(\mathrm{~N})$ and the sample size was at least $n=17729$. A total of 17812 participants (10939 females, 6873 males) were included in this retrospective observational study. Sociodemographic characteristics, diseases, used medication and smoking, height, weight, waist and hip circumferences ( $\mathrm{WaC}$ and $\mathrm{HC}$ ) were recorded from the files.

Results: The mean age of all subjects was 46.1 years, the mean BMI was $28.1 \mathrm{~kg} / \mathrm{m}^{2}$ with a mean WaC of $91.3 \mathrm{~cm}, \mathrm{HC}$ of $104.7 \mathrm{~cm}$, WHR of 0.87 . The prevalence of obesity in Bursa was found to be $32.2 \%$ ( $37.8 \%$ in females and $23.3 \%$ in males) according to BMI, $63.2 \%$ (69.7\% in females, $52.9 \%$ in males) according to waist and hip circumferences.

Conclusions: Preventive measures should be taken by health authorities to prevent the rapid increase in general and abdominal obesity that may lead to serious comorbidities.
\end{abstract}

KEYWORDS: Abdominal obesity, Obesity, Metabolic syndrome.

doi: https://doi.org/10.12669/pjms.35.4.235

How to cite this:

Goktas O, Ersoy C, Ercan I, Can FE. General and abdominal obesity prevelances and their relations with metabolic syndrome components. Pak J Med Sci. 2019;35(4):945-950. doi: https://doi.org/10.12669/pjms.35.4.235

This is an Open Access article distributed under the terms of the Creative Commons Attribution License (http://creativecommons.org/licenses/by/3.0), which permits unrestricted use, distribution, and reproduction in any medium, provided the original work is properly cited.

1. Dr. Olgun Goktas, Associate Professor,

Family Health Center, Nilufer,

2. Prof. Dr. Canan Ersoy,

Department of Internal Medicine,

Division of Endocrinology and Metabolism,

Faculty of Medicine,

3. Prof. Dr. Ilker Ercan,

Department of Biostatistics,

Faculty of Medicine,

4. Fatma Ezgi Can, Bsc

Department of Biostatistics,

Institute of Health Science,

1-4: Uludag University,

Bursa, Turkey.

Correspondence:

Dr. Olgun Goktas,

Associate Professor,

Uludag University Family Health Center,

16059, Gorukle Campus-Nilufer,

Bursa, Turkey.

E-mail: olgun_goktas@hotmail.com

* Received for Publication:

December 20, 2018

* Revision Received:

* Revision Accepted:

\section{INTRODUCTION}

Obesity is an important health problem affecting individual and society all over the world, as well as in our country, due to its association with increased morbidity and mortality. Other than dietary and physical activity habits, there are many factors affecting body weight increment like age, gender, marital status, education level, accompanying illnesses and drugs used. ${ }^{1,2}$

Assessment of obesity is mostly made by measuring body mass index (BMI) which is a parameter of general obesity. Beside this, obesity is also assessed by measurement of waist and hip circumferences $(\mathrm{WaC}, \mathrm{HC})$ and calculation of waist to hip ratio (WHR).3,4

Abdominal obesity has much more health risk according to the fat excess in other regions of the body. Evaluation of optimal WaC is made differently by organizations like International Diabetes Federation (IDF) and World Health 
Organization (WHO). WaC and WHR are closely related to metabolic syndrome components which are abdominal obesity, insulin resistance and related disorders. Metabolic syndrome includes the components such as abdominal obesity, glucose intolerance, dyslipidemia, hypertension and atherosclerotic heart disease. Each component has harmful effects on human health, morbidity and mortality. ${ }^{4-8}$

There are different national studies conducted in our country evaluating obesity prevelance in adults from 1990 and 2010. In these studies obesity prevelance ranges between $18.8 \%$ to $39.7 \%$ with an increasing rate in recent years. ${ }^{2,9}$ In a previous study conductedby us and reported in 2005, obesity prevelance was found to be $35.5 \%$ in our city Bursa and we wanted to check this prevalence. ${ }^{10}$

\section{METHODS}

In the study, the population size of Bursa province $(\mathrm{N}=2901396)$ was accepted as the main population and the sample size was at least $n=17729$ at the level of significance of $\mathrm{d}=0.009$ and at the level of significance of $a=0.01$ with reference to $36 \%$ obesity incidence rate. ${ }^{9}$ Sampling was based on size proportional stratified sampling. A total of 26356 individuals from 19 databases of family health centers identified by stratification were included in the study. When the subjects with missing data were excluded from the study, a total of 17812 participants were included.

Age, gender, marital status, educational status, accompanying diseases, medications used, height, weight, $\mathrm{WaC}$ and $\mathrm{HC}$ were recorded from the files. BMI and WHR were calculated. BMI was computed by dividing body weight in kilograms to height in meters squared. The WHR was calculated by the division of $\mathrm{WaC}$ to $\mathrm{HC}$ as an index of abdominal obesity., The prevalences of obesity in our study were assessed according to BMI, WaC (IDF and WHO criterias) and WHR. Obesity classification according to BMI was $\geq 30 \mathrm{~kg} / \mathrm{m}^{2}$ for both genders, according to $\mathrm{WaC}$ defined by IDF was $\geq 94 \mathrm{~cm}$ for males and $\geq 80 \mathrm{~cm}$ for females and by WHO was $\geq 102$ $\mathrm{cm}$ for males and $\geq 88 \mathrm{~cm}$ for females. According to WHR, subjects were considered as obese if $>0.9$ for males and $>0.8$ for females. ${ }^{11,12}$

The data of the consecutive adult residents of Bursa who were admitted to the family health centers due to routine control programmes from the $1^{\text {st }}$ January to the $31^{\text {st }}$ December 2016 were evaluated retrospectively. The data from the records of subjects older than 18 years of age were included in the study.

The necessary physical examinations and hormonal evaluations were performed to exclude endocrinological causes for obesity. Medication records were evaluated. Data of subjects with endocrine obesity and with usage of drugs that increase insulin resistance like steroids were not included in the study.

With reference to obesity evaluation according to BMI index, factors affecting the risk of obesity were investigated by backward binary logistic regression. Binary logistic regression analysis indicated regression coefficients, standard error of coefficients, odds ratio and 95\% confidence intervals. The effect size was calculated for the mean values $d=\left(\mu_{2}-\mu_{1}\right) / \sigma$ pooled for the ratios $h=\varphi_{1}-\varphi_{2}$ and $\varphi_{i}=2 \arcsin \sqrt{ } P_{i}{ }^{13,14}$ Effect size value was evaluated according to 0.2 low, 0.5 moderate, 0.8 high, 1.3 very high. ${ }^{15} \mathrm{P}<0.05$ was considered statistically significant. The analysis was done in the IBM SPSS v.20 program (Uludağ University).

\section{RESULTS}

Data from the files of a total of 17812 subjects (10939 females; 61.41\%, 6873 males; 38,59\%) were included in the study. The mean age of all subjects was $46.13 \pm 18.52$ years, the mean BMI was $28.10 \pm 9.36$ $\mathrm{kg} / \mathrm{m}^{2}$ with a mean $\mathrm{WaC}$ of $91.33 \pm 14.74 \mathrm{~cm}, \mathrm{HC}$ of $104.70 \pm 11.74 \mathrm{~cm}, \mathrm{WHR}$ of $0.87 \pm 0.10$ (Table-I).

The prevalence of obesity in Bursa was found to be $32.2 \%$ (37.8\% in females, $23.3 \%$ in males) according to BMI, $63.2 \%$ (69.7\% in females, $52.9 \%$ in males) according to WaC-IDF criteria, $44.4 \%$ (53.6\% in females, $29.8 \%$ in males) according to WaCWHO criteria and $64.1 \%(67.8 \%$ in females, $58.4 \%$ in males) according to WHR (Table-II).

The risk of obesity increased 1.003 fold with increasing age. Female subjects were 1.976 times

Table-I: The demographic features of both genders and all participants.

\begin{tabular}{lccc}
\hline Variables & $\begin{array}{c}\text { Females } \\
(n=10939)\end{array}$ & $\begin{array}{c}\text { Males } \\
(n=6873)\end{array}$ & $\begin{array}{c}\text { All participants } \\
(n=17812)\end{array}$ \\
\hline Age (years) & $45.92 \pm 18.17$ & $46.45 \pm 19.06$ & $46.13 \pm 18.52$ \\
Height $(\mathrm{cm})$ & $158.05 \pm 18.17$ & $172.63 \pm 10.72$ & $163.67 \pm 17.25$ \\
Weight $(\mathrm{kg})$ & $72.61 \pm 15.12$ & $80.43 \pm 14.47$ & $75.63 \pm 15.35$ \\
BMI $\left(\mathrm{kg} / \mathrm{m}^{2}\right)$ & $28.75 \pm 9.53$ & $27.09 \pm 9$ & $28.10 \pm 9.36$ \\
WaC $(\mathrm{cm})$ & $89.38 \pm 15.21$ & $94.37 \pm 13.42$ & $91.33 \pm 14.74$ \\
$\mathrm{HC}(\mathrm{cm})$ & $106.13 \pm 12.52$ & $102.46 \pm 9.99$ & $104.70 \pm 11.74$ \\
WHR & $0.84 \pm 0.09$ & $0.92 \pm 0.09$ & $0.87 \pm 0.10$ \\
\hline
\end{tabular}

BMI: body mass index, WaC: waist circumference, HC: hip circumference, WHR: waist to hip ratio. 
Table-II: Obesity rates according to BMI, WaC and WHR criterias in both genders and all participants.

\begin{tabular}{lccc}
\hline Variables, $\%(n)$ & Females $(n=10939)$ & Males $(n=6873)$ & All participants $(n=17812)$ \\
\hline BMI $\left(\mathrm{kg} / \mathrm{m}^{2}\right)$ & $37.8(4090 / 10806)$ & $23.3(1597 / 6857)$ & $32.2(5687 / 17663)$ \\
WaC-IDF $(\mathrm{cm})$ & $69.7(5860 / 8402)$ & $52.9(2842 / 5372)$ & $63.2(8702 / 13774)$ \\
WaC-WHO $(\mathrm{cm})$ & $53.6(4507 / 8402)$ & $29.8(1602 / 5372)$ & $44.4(6109 / 13774)$ \\
WHR & $67.8(5690 / 8391)$ & $58.4(3134 / 5366)$ & $64.1(8824 / 13757)$ \\
\hline
\end{tabular}

BMI: Body mass index, WaC: Waist circumference, WHR: Waist to hip ratio.

Table-III: Investigation of risk factors affecting obesity $(\mathrm{n}=12505)$.

\begin{tabular}{lcccccc}
\hline & $\beta$ & SE of $(\beta)$ & Exp $(\beta)$ & \multicolumn{2}{c}{$95 \%$ CI } & p value \\
\hline Age & 0.003 & 0.001 & 1.003 & 1.001 & 1.006 & 0.014 \\
Gender (Ref: Male) & 0.681 & 0.049 & 1.976 & 1.795 & 2.174 & $\mathrm{p}<0.001$ \\
Marital Status (Ref: Single) & 0.476 & 0.051 & 1.609 & 1.455 & 1.780 & $\mathrm{p}<0.001$ \\
Education (Ref: High school and university) & 0.595 & 0.052 & 1.812 & 1.635 & 2.008 & $\mathrm{p}<0.001$ \\
Previous obesity history (Ref: No) & 1.845 & 0.132 & 6.326 & 4.882 & 8.197 & $\mathrm{p}<0.001$ \\
Smoking (Ref: No) & 0.214 & 0.066 & 1.238 & 1.088 & 1.409 & $\mathrm{p}<0.001$ \\
Hypertension (Ref: No) & 0.653 & 0.056 & 1.921 & 1.721 & 2.144 & $\mathrm{p}<0.001$ \\
Dyslipidemia (Ref: No) & 0.196 & 0.069 & 1.217 & 1.064 & 1.392 & 0.004 \\
Hypothyroidism (Ref: No) & 0.219 & 0.108 & 1.245 & 1.007 & 1.539 & 0.043 \\
Antidiabetic drugs(Ref: No) & 0.485 & 0.056 & 1.624 & 1.454 & 1.814 & $\mathrm{p}<0.001$ \\
\hline
\end{tabular}

* The regression model is statistically significant $(\mathrm{p}<0.001)$.

more likely to be obese compared to male subjects, married ones 1.609 times compared to singles and those having lower education level 1.812 times compared to higher education level subjects. The risk of obesity in those with previous obesity history was 6.326 times higher compared to those without, smokers 1.238 times compared to nonsmokers, hypertensives 1.921 fold compared to normotensives, dyslipidemics 1.217 fold compared to normolipidemics and hypothyroids 1.245 fold compared to euthyroids, diabetics with antidiabetic drug usage 1.624 times compared to nondiabetics (Table-III).

When the effective size of age showed a high effect on $\mathrm{WaC}-\mathrm{WHO}$ in females and moderate effect in males. When the effect size of type 2 diabetes was evaluated it had low effect on WaC-IDF and WaCWHO in males and moderate effect in females. Dyslipidemia was evaluated accoprding to the WaC-IDF in females which had a moderate effect. Atherosclerotic heart disease was found to have a low effect on all obesity parameters in both genders (Table-IV).

\section{DISCUSSION}

Our study indicated high general and abdominal obesity in our population affecting the presence of components of metabolic syndrome. The prevelance of obesity increased as the cut off value for $\mathrm{WaC}$ was lowered as in WaC-IDF. Whatever criteria chosen
(WHR, WaC-IDF and WaC-WHO) abdominal obesity seemed to be the prominent problem concerning metabolic syndrome components in both genders but especially in female gender. According to these results our hypothesis has been confirmed.

According to Centers for Disease Control and Prevention National Center for Health Statistics (NCHS) the prevalence of obesity was $36.5 \%$ in United States among adults during 2011-2014. The prevalence of obesity among middle aged adults (40-59 years) was the highest $(40.2 \%)$ among all age groups, in both genders $(42.1 \%$ for females and $38.3 \%$ for males). ${ }^{16}$

In a study conducted in European countries, the prevalence of obesity in females ranged between 6.2 to $36.5 \%$ and males between 4 to $28.3 \%$ among different countries. ${ }^{1}$ The prevalence of obesity in our country was $36 \%$ according to TURDEP-II study. Between TURDEP-I and TURDEP-II surveys, average BMI increased from 26.6 to $28.6 \mathrm{~kg} / \mathrm{m}^{2}$ and average waist from 87.2 to $94.5 \mathrm{~cm}$ over 12 years in Turkey. The rate of increase for abdominal obesity was $35 \%$ compared to TURDEP-I. ${ }^{9}$

In our present study, the mean age of all subjects was 46 years. Their mean BMI was $28.1 \mathrm{~kg} / \mathrm{m}^{2}$ with a mean $\mathrm{WaC}$ of $91.3 \mathrm{~cm}, \mathrm{HC}$ of $104.7 \mathrm{~cm}, \mathrm{WHR}$ of 0.87. Similar to data reported in the literature, in our present study, we found a high prevalence of obesity in Bursa as $32.2 \%$ (37.8\% in females and 
Table-IV: Assessments of obese and non-obese female (a) and male (b) subjects according to effect size of their risk factors as metabolic syndrome components on general and abdominal obesity indexes.

\begin{tabular}{|c|c|c|c|c|}
\hline \multirow[b]{2}{*}{ Variables } & \multirow[b]{2}{*}{ Indexes } & \multicolumn{3}{|c|}{ Female subjects } \\
\hline & & Obesity present & Obesity absent & $E S \pm S D \quad C I \% 95$ \\
\hline \multirow[t]{4}{*}{ Age } & BMI & $52.34 \pm 16.13(51.84 ; 52.83)$ & $42.24 \pm 18.27(41.81 ; 42.68)$ & $0.58 \pm 0.02(0.538 ; 0.617)$ \\
\hline & WHR & $51.09 \pm 17.825(50.62 ; 51.55)$ & $37.12 \pm 14.153(36.58 ; 37.65)$ & $0.83 \pm 0.024(0.787 ; 0.882)$ \\
\hline & WaC-IDF & $52.53 \pm 16.408(52.11 ; 52.95)$ & $32.91 \pm 16.408(32.39 ; 33.42)$ & $1.26 \pm 0.026(1.212 ; 1.312)$ \\
\hline & WaC-WHO & $55.01 \pm 15.59(54.55 ; 55.46)$ & $36.86 \pm 15.45(36.37 ; 37.34)$ & $1.17 \pm 0.024(1.123 ; 1.216)$ \\
\hline \multirow{4}{*}{$\begin{array}{l}\text { Type } 2 \\
\text { diabetes }\end{array}$} & BMI & $0.26 \pm 0.007(0.245 ; 0.272)$ & $0.12 \pm 0.004(0.115 ; 0.130)$ & $0.35 \pm 0.02(0.31 ; 0.39)$ \\
\hline & WHR & $0.22 \pm 0.005(0.208 ; 0.23)$ & $0.06 \pm 0.005(0.05 ; 0.067)$ & $0.49 \pm 0.024(0.441 ; 0.534)$ \\
\hline & WaC-IDF & $0.23 \pm 0.005(0.217 ; 0.239)$ & $0.03 \pm 0.003(0.022 ; 0.035)$ & $0.65 \pm 0.024(0.607 ; 0.703)$ \\
\hline & WaC-WHO & $0.27 \pm 0.007(0.255 ; 0.281)$ & $0.05 \pm 0.004(0.045 ; 0.059)$ & $0.63 \pm 0.022(0.586 ; 0.674)$ \\
\hline \multirow[t]{4}{*}{ Hypertension } & $\mathrm{BMI}$ & $0.42 \pm 0.008(0.404 ; 0.434)$ & $0.20 \pm 0.005(0.191 ; 0.21)$ & $0.48 \pm 0.02(0.44 ; 0.52)$ \\
\hline & WHR & $0.38 \pm 0.006(0.365 ; 0.39)$ & $0.14 \pm 0.007(0.131 ; 0.158)$ & $0.54 \pm 0.024(0.45 ; 0.591)$ \\
\hline & WaC-IDF & $0.93 \pm 0.003(0.923 ; 0.937)$ & $0.07 \pm 0.005(0.061 ; 0.081)$ & $2.07 \pm 0.029(2.011 ; 2.123)$ \\
\hline & $\mathrm{WaC}-\mathrm{WHO}$ & $0.46 \pm 0.007(0.443 ; 0.472)$ & $0.12 \pm 0.005(0.113 ; 0.134)$ & $0.77 \pm 0.023(0.722 ; 0.811)$ \\
\hline \multirow[t]{4}{*}{ Dyslipidemia } & BMI & $0.15 \pm 0.006(0.14 ; 0.162)$ & $0.07 \pm 0.003(0.064 ; 0.076)$ & $0.26 \pm 0.02(0.22 ; 0.30)$ \\
\hline & WHR & $0.14 \pm 0.005(0.128 ; 0.146)$ & $0.041 \pm 0.004(0.034 ; 0.049)$ & $0.35 \pm 0.024(0.304 ; 0.40)$ \\
\hline & WaC-IDF & $0.14 \pm 0.005(0.135 ; 0.153)$ & $0.02 \pm 0.003(0.014 ; 0.025)$ & $0.50 \pm 0.024(0.453 ; 0.548)$ \\
\hline & $\mathrm{WaC}-\mathrm{WHO}$ & $0.17 \pm 0.006(0.154 ; 0.176)$ & $0.04 \pm 0.003(0.032 ; 0.044)$ & $0.44 \pm 0.022(0.400 ; 0.487)$ \\
\hline \multirow{4}{*}{$\begin{array}{l}\text { Atherosclerotic } \\
\text { heart disease }\end{array}$} & BMI & $0.12 \pm 0.005(0.107 ; 0.127)$ & $0.06 \pm 0.003(0.05 ; 0.061)$ & $0.22 \pm 0.02(0.18 ; 0.26)$ \\
\hline & WHR & $0.11 \pm 0.004(0.098 ; 0.114)$ & $0.03 \pm 0.003(0.026 ; 0.039)$ & $0.30 \pm 0.023(0.255 ; 0.347)$ \\
\hline & WaC-IDF & $0.11 \pm 0.004(0.102 ; 0.118)$ & $0.02 \pm 0.003(0.012 ; 0.022)$ & $0.41 \pm 0.024(0.365 ; 0.459)$ \\
\hline & WaC-WHO & $0.13 \pm 0.005(0.117 ; 0.136)$ & $0.03 \pm 0.003(0.025 ; 0.035)$ & $0.38 \pm 0.022(0.336 ; 0.423)$ \\
\hline \multicolumn{5}{|l|}{ b) } \\
\hline & & \multicolumn{3}{|c|}{ Male subjects } \\
\hline Variables & Indexes & Obesity $(+)$ present & Obesity (-) absent & $E S \pm S S S D C I \% 95$ \\
\hline \multirow[t]{4}{*}{ Age } & BMI & $53.24 \pm 15.99(52.45 ; 54.02)$ & $44.38 \pm 19.42(43.86 ; 44.91)$ & $0.47 \pm 0.03(0.42 ; 0.53)$ \\
\hline & WHR & $53.02 \pm 16.725(52.42 ; 53.60)$ & $37.10 \pm 18.356(36.33 ; 37.86)$ & $0.91 \pm 0.029(0.857 ; 0.971)$ \\
\hline & WaC-IDF & $53.78 \pm 16.246(53.18 ; 54.37)$ & $38.20 \pm 18.712(37.47 ; 38.93)$ & $0.89 \pm 0.029(0.837 ; 0.949)$ \\
\hline & $\mathrm{WaC}-\mathrm{WHO}$ & $55.12 \pm 15.389(54.37 ; 55.88)$ & $42.75 \pm 19.334(42.13 ; 43.37)$ & $0.68 \pm 0.031(0.618 ; 0.738)$ \\
\hline Type 2 & BMI & $0.23 \pm 0.011(0.209 ; 0.250)$ & $0.15 \pm 0.005(0.136 ; 0.155)$ & $0.22 \pm 0.03(0.16 ; 0.27)$ \\
\hline \multirow[t]{3}{*}{ diabetes } & WHR & $0.22 \pm 0.007(0.203 ; 0.232)$ & $0.06 \pm 0.005(0.047 ; 0.066)$ & $0.49 \pm 0.03(0.44 ; 0.55)$ \\
\hline & WaC-IDF & $0.22 \pm 0.008(0.209 ; 0.24)$ & $0.07 \pm 0.005(0.057 ; 0.077)$ & $0.46 \pm 0.028(0.409 ; 0.517)$ \\
\hline & WaC-WHO & $0.26 \pm 0.011(0.24 ; 0.283)$ & $0.10 \pm 0.005(0.093 ; 0.113)$ & $0.42 \pm 0.03(0.36 ; 0.479)$ \\
\hline \multirow[t]{4}{*}{ Hypertension } & BMI & $0.35 \pm 0.012(0.322 ; 0.368)$ & $0.23 \pm 0.006(0.220 ; 0.243)$ & $0.25 \pm 0.03(0.20 ; 0.31)$ \\
\hline & WHR & $0.38 \pm 0.009(0.361 ; 0.395)$ & $0.11 \pm 0.007(0.099 ; 0.126)$ & $0.64 \pm 0.03(0.58 ; 0.70)$ \\
\hline & WaC-IDF & $0.38 \pm 0.009(0.358 ; 0.394)$ & $0.15 \pm 0.007(0.13 ; 0.16)$ & $0.54 \pm 0.028(0.481 ; 0.590)$ \\
\hline & $\mathrm{WaC}-\mathrm{WHO}$ & $0.42 \pm 0.012(0.396 ; 0.444)$ & $0.20 \pm 0.007(0.19 ; 0.216)$ & $0.48 \pm 0.03(0.416 ; 0.534)$ \\
\hline \multirow[t]{4}{*}{ Dyslipidemia } & BMI & $0.16 \pm 0.009(0.138 ; 0.174)$ & $0.09 \pm 0.004(0.079 ; 0.094)$ & $0.21 \pm 0.03(0.16 ; 0.27)$ \\
\hline & WHR & $0.16 \pm 0.006(0.143 ; 0.168)$ & $0.04 \pm 0.004(0.033 ; 0.05)$ & $0.40 \pm 0.03(0.35 ; 0.46)$ \\
\hline & WaC-IDF & $0.16 \pm 0.007(0.144 ; 0.17)$ & $0.06 \pm 0.005(0.05 ; 0.069)$ & $0.32 \pm 0.028(0.267 ; 0.375)$ \\
\hline & WaC-WHO & $0.18 \pm 0.01(0.157 ; 0.195)$ & $0.08 \pm 0.004(0.071 ; 0.088)$ & $0.29 \pm 0.03(0.236 ; 0.354)$ \\
\hline \multirow{4}{*}{$\begin{array}{l}\text { Atherosclerotic } \\
\text { heart disease }\end{array}$} & $\mathrm{BMI}$ & $0.14 \pm 0.009(0.122 ; 0.156)$ & $0.10 \pm 0.004(0.089 ; 0.105)$ & $0.13 \pm 0.03(0.08 ; 0.19)$ \\
\hline & WHR & $0.16 \pm 0.006(0.143 ; 0.168)$ & $0.05 \pm 0.005(0.038 ; 0.056)$ & $0.37 \pm 0.03(0.32 ; 0.43)$ \\
\hline & WaC-IDF & $0.16 \pm 0.007(0.143 ; 0.170)$ & $0.06 \pm 0.005(0.05 ; 0.069)$ & $0.32 \pm 0.028(0.265 ; 0.373)$ \\
\hline & WaC-WHO & $0.17 \pm 0.009(0.154 ; 0.191)$ & $0.08 \pm 0.005(0.075 ; 0.093)$ & $0.27 \pm 0.03(0.21 ; 0.33)$ \\
\hline
\end{tabular}

Effect size (ES): 0.2 low, 0.5 moderate, 0.8 high, 1.3 very high.

BMI: body mass index, WaC: waist circumference, WHR: waist-to-hip ratio. 
$23.3 \%$ in males) according to BMI. Abdominal obesity prevalences were high both with WaC-IDF and $\mathrm{WaC}-\mathrm{WHO}$ criterias; $63.2 \%$ (69.7\% in females, $52.9 \%$ in males) and $44.4 \%$ (53.6\% for females, $29.8 \%$ for males) respectively. In our present study, females were more obese compared to males both generally and abdominally.

Gender, age, marital status, previous obesity history, education level, accompanying illnesses like diabetes, hypertension, dyslipidemia, atherosclerotic heart disease, hypothyroidism, medications and smoking are known to be the risk factors of obesity. ${ }^{1,2}$ In our previous study conducted in 2005, sedentary life style and dyslipidemia in males, being unemployed, having lower level of education and having hypertension in females and familial obesity in both genders were found to be related to increased obesity risk..$^{10}$ In our present study, age, gender, marital status, previous obesity history, hypertension, dyslipidemia, smoking, hypothyroidism and antidiabetic drug usage in diabetics were found to be significant risk factors for obesity development.

The underlying cause of the metabolic syndrome is still debatable. Both general and abdominal obesities contribute to hypertension, dyslipidemia and hyperglycemia and are independently associated with higher cardiovascular disease risk. ${ }^{16}$ The risk of serious health consequences in the form of components of metabolic syndrome has been shown to rise with an increase in BMI, but an excess of body fat in the abdomen is more indicative of the metabolic syndrome profile than BMI. ${ }^{17,18}$ In the San Antonio Heart Study, the baseline $\mathrm{WaC}$ of the subjects who did not progress to type 2 diabetes was $88.7 \mathrm{~cm}$ while who developed type 2 diabetes in 7 years of follow up was $98 \mathrm{cms}$. In this study $\mathrm{WaC}$ was found to be the strongest predictor of type 2 diabetes. In the same study BMI, fasting insulin and triglyceride levels predicted the development of hypertension indicating the importance of overall adiposity ${ }^{19}$ In Nurses Health Study a WaC of 96.5 $\mathrm{cm}$ or more was associated with a relative risk of 3.06 for coronary heart disease. ${ }^{20}$

\section{CONCLUSION}

Our results indicated that, both general and abdominal obesities were much more prominent in female gender. All three criterias indicating abdominal obesity namely; WHR, WaC-IDF and $\mathrm{WaC}-\mathrm{WHO}$ could be preferred for risk determination of metabolic syndrome components. Age, gender, marital status, previous obesity history, hypertension, dyslipidemia, smoking, hypothyroidism and antidiabetic drug usage in diabetic subjects were found to be significant risk factors for obesity development.

Since aging and gender are unmodifyable risk factors, life style changes should be encouraged in the population and preventive measures should be taken by the health authorities to prevent obesity.

\section{ACKNOWLEDGEMENTS}

We would like to thank ARGEV (The Turkish Family Medicine Research Development and Education Foundation) providing education before the study for their cooperation and our colleagues and family physicians who have contributed to this study by participating in all the districts of Bursa province;

Murat Girginer: Ertuğrulgazi Family Health Center, Yıldırım, Bursa, Turkey

Enes Mesutoğlu: Ali Bakgör Family Health Center, Osmangazi, Bursa, Turkey

Erhan Kutsal: Esenevler Family Health Center, Yıldırım, Bursa, Turkey

Taner Ödemiş: $\quad$ Atıcılar Family Health Center, Osmangazi, Bursa, Turkey

Filiz Ödemiş: $\quad$ Atıcılar Family Health Center, Osmangazi, Bursa, Turkey

H. Burcu Bulunmaz: Beşevler Family Health Center, Nilüfer, Bursa, Turkey Bilgen Küçük: Küplüpınar Family Health Center, Osmangazi, Bursa, Turkey

Funda Arpacı: Küplüpınar Family Health Center, Osmangazi, Bursa, Turkey

Tülay Gündüzcü: Beşevler Family Health Center, Nilüfer, Bursa, Turkey

Fahri Özaydın: Eşref Dinçer Family Health Center, Gemlik, Bursa, Turkey Alp Oktay: Demirtaş Family Health Center, Osmangazi, Bursa, Turkey

Yusuf Karayürek: Eşref Dinçer Family Health Center, Gemlik, Bursa, Turkey Esad Uyanık: $\quad$ Yenişehir Number 3 Family Health Center, Yenişehir, Bursa, Turkey

Olgun Göktaş: Uludağ University Family Health Center, Nilüfer, Bursa, Turkey 
Nevin Özdilek: $\quad$ Orkent Family Health Center, Orhangazi, Bursa, Turkey

Atıl Başar Bozkurt: Zeytinbağı Family Health Center, Mudanya, Bursa, Turkey

Aykut Ardıç: $\quad$ Siteler Family Health Center, Yenişehir, Bursa, Turkey

Şenay Karataş: $\quad$ Ş. Üst. A. Köroğlu Family Health Center, Osmangazi, Bursa, Turkey

Emre Yalçıntaş: Büyükorhan Family Health Center, Büyükorhan, Bursa, Turkey

Disclosure: We authors, we are reporting that there is no conflict of interest.

\section{Grant Support \& Financial Disclosures: None.}

\section{REFERENCES}

1. Berghofer A, Pischon T, Reinhold T, Apovian CM, Sharma AM, Willich SN. Obesity prevalence from a European perspective: a systematic review. BMC Public Health. 2008;8:200. doi: 10.1186/1471-2458-8-200.

2. Erem C. Prevalence of Overweight and Obesity in Turkey. IJC Metabolic Endocrine. 2015;8:38-41. doi: 10.1016/j. ijcme.2015.07.002.

3. Taskiran Tatar B, Ersoy C, Kacan T, Kirhan E, Sarandol E, Sigirli D, et al. Neck and Wrist Circumferences Propose a Reliable Approach to Qualify Obesity and Insulin Resistance. Med-Sci. 2014;3:1013-1025. doi: 10.5455/ medscience.2013.02.8100.

4. Saqlain M, Saeed S, Fiaz M, Mahmood A, Ghani RA, Jabeen $\mathrm{S}$, et al. Screening of cardiometabolic risks clustering in young Pakistani adults classified by anthropometric traits. J Pak Med Assoc. 2017;67:1825-1832.

5. Maffetone PB, Laursen PB. The Prevalence of Overfat Adults and Children in the US. Front Public Health. 2017;5:290 doi: 10.3389/fpubh.2017.00290.

6. Ramirez-Velez R, Correa-Bautista JE, Sanders-Tordecilla A, Ojeda-Pardo ML, Cobo-Mejia EA, Castellanos-VegaRDP, et al. Percentage of Body Fat and Fat Mass Index as a Screening Tool for Metabolic Syndrome Prediction in Colombian University Students. Nutrients. 2017;9:1009 doi: 10.3390/ nu9091009.

7. Parikh RM, MohanV. Changing definitions of metabolic syndrome. Indian J Endocrinol Metab. 2012;16:7-12. doi: 10.4103/2230-8210.91175.

8. Kahn R, Buse J, Ferrannini E, Stern M. American Diabetes Association; European Association for the Study of Diabetes. The metabolic syndrome: time for a critical appraisal: Joint statement from the American Diabetes Association and the Eur Assoc Stud Diabet Care. 2005;28:2289-2304.
9. Satman I, Omer B, Tutuncu Y, Kalaca S, Gedik S, Dinccag $\mathrm{N}$, et al. TURDEP-II Study Group. Twelve-year trends in the prevalence and risk factors of diabetes and prediabetes in Turkish Adults. Eur J Epidemiol. 2013;28:169-180. doi: 10.1007/s10654-013-9771-5.

10. Ersoy C, Imamoglu S, Tuncel E, Erturk E, Ercan I. Comparison of the factors that influence obesity prevalence in three district municipalities of the same city with different socioeconomical status: a survey analysis in an urban Turkish population. Prev Med. 2005;40:181-188 doi: 10.1016/j.ypmed.2004.05.018.

11. Waist circumference and waist-hip ratio: Report of a WHO expert consultation 2008,27. Geneva, Switzerland: WHO Press.

12. Baik I. Optimal cutoff points of waist circumference for the criteria of abdominal obesity: comparison with the criteria of the International Diabetes Federation. Circ J. 2009;73:20682075 https:// doi.org/10.1253/circj.CJ-09-0303.

13. Huedo-Medina TB, Sanchez-Meca J, Marin-Martinez F, Botella J. Assessing heterogeneity in meta-analysis: $Q$ statistic or I2 index? Psychol Methods. 2006;11:193-206 doi: 10.1037/1082-989X.11.2.193.

14. Cohen J. Statistical power analysis for behavioral sciences. $2^{\text {nd }}$ edition. Lawrence Erlbaum associates, publishers: New York. 1988.

15. Sullivan GM, Feinn R. Using effect size-or why the $p$ value is not enough. J Grad Med Edu. September 2012. doi: 10.4300/ JGME-D-12-00156.1.

16 Ogden CL, Carroll MD, Kit BK, Flegal KM. Prevalence of Obesity Among Adults: United States, 2011-2012 NCHS Data Brief, No. 131, 2013: https://www.cdc.gov/nchs/ data/databriefs/db131.pdf.

17. Swarup S, Zeltser R. Metabolic Syndrome. Treasure Island (FL): StatPearls Publishing; 2017.

18. Pouliot MC, Despres JP, Lemieux S, Moorjani S, Bouchard C, Tremblay A, et al. Waist circumference and abdominal sagittal diameter: best simple anthropometric indexes of abdominal visceral adipose tissue xaccumulation and related cardiovascular risk in men and women. Am J Cardiol. 1994;73:460-468. doi: 10.1016/0002-9149(94)90676-9.

19. Haffner SM. Obesity and the metabolic syndrome: the San Antonio Heart Study. Br J Nutr. 2000;83(Suppl 1):S67-S70.

20. Lebovitz HE. Clinician's Manual on Insulin resistance. Science press Ltd. London UK; 2002.

\section{Authors' Contribution:}

OG, CE, IE, FEC: Conceived, designed and did statistical analysis \& editing of manuscript.

OG, CE: Did data collection and manuscript writing.

OG: Did review and final approval of manuscript. 